\title{
Rantai Pasar Ikan Sagela Asap (Hemirhamphus sp.) Asal Provinsi Gorontalo
}

\section{(Marketing channels of smoked halfbeaks from Gorontalo Province)}

\author{
Ni’mawati Syariah $^{1}$ dan Asruddin ${ }^{2}$ \\ ${ }^{1}$ Program Studi Budidaya Perairan, Fakultas Ilmu-Ilmu Pertanian \\ Universitas Muhammadiyah Gorontalo \\ Email : ni'ma.syariah@umgo.ac.id
}

\begin{abstract}
ABSTRAK
Penelitian ini bertujuan untuk mengetahui saluran pemasaran, margin pemasaran, dan efisiensi pemasaran ikan sagela asap di Provinsi Gorontalo. Penelitian ini dilaksanakan di propinsi Gorontalo pada bulan Mei- Agustus 2018. Jenis penelitian yang digunakan adalah sensus dengan responden dalam penelitian ini adalah produsen sebanyak 8 orang, pedagang besar 5 orang, supplier 1 orang dan 4 pedagang pengecer yang diambil secara sampling jenuh. Penelitian ini dilakukan dengan menggunakan daftar pertanyaan sebagai alat pengumpulan data. Data dianalisis dengan analisis deskriptif, marjin dan efisiensi pemasaran.. Hasil penelitian menunjukkan bahwa bentuk Saluran tata niaga ikan sagela asap asal provinsi Gorontalo yaitu mulai dari produsen kemudian menjualnya ke pedagang besar, supplier luar propinsi dan pedagang pengecer untuk seterusnya ke konsumen. Margin tertinggi ikan asap asal Desa Pasalae sebesar Rp 8.000,-, dan margin tertinggi ikan asap asal Desa Bangga dan Desa Pentadu Barat sebesar Rp 3.000,-. Saluran pemasaran yang paling efisien untuk ikan sagela asap asal Desa Pasalae dan Pentadu Barat adalah saluran yang langsung dari produsen ke konsumen sedangkan di Desa Bangga saluran pemasaran yang efisien adalah saluran yang dari produsen ke pedagang besar kemudian ke pedagang pengecer selanjutnya ke konsumen.
\end{abstract}

Kata Kunci : Rantai Pasar, Marjin, Efisiensi Pemasaran, Ikan Sagela Asap

\section{ABSTRACT}

This study aims to determine the marketing channels, marketing margins, and marketing efficiency of smoked Halfbeaks in Gorontalo Province. This research was conducted in Gorontalo province from May-August 2018. The type of research used was census with respondents in this study were 8 producers, 5 wholesalers, 1 supplier and 4 retailers that were taken in saturated sampling. This research was conducted using a questionnaire as a data collection tool. The data were analyzed by descriptive analysis, margin and marketing efficiency. The results showed that the form of the smoked Halfbeaks trade system from Gorontalo province, starting from the producer and then selling it to wholesalers, outside province suppliers and retailers to the consumer. The highest margin of smoked Halfbeaks from Pasalae Village is IDR. 8,000, - and the highest margin of smoked Halfbeaks from the Bangga and West Pentadu Villages is IDR. 3,000. The most efficient marketing channel for Smoked Halfbeaks from Pasalae and Pentadu Barat villages is a channel that is directly from producers to consumers while in the Bangga Village, the efficient marketing channels are channels from producers to wholesalers then to retailers then to consumers.

Keywords: Market Chains, Margins, Marketing Efficiency, Smoked Halfbeaks 


\section{PENDAHULUAN}

Ikan merupakan salah satu komoditi yang mudah busuk. Oleh karena itu diperlukan suatu upaya penanganan untuk menghambat pembusukan dengan cara pengawetan dan pengolahan antara lain pengasapan untuk menghambat pembusukan dan memberikan aroma dengan cita rasa yang khas. Menurut sulistijowati et al. (2011) pengasapan (smoking) merupakan upaya penyerapan bermacam-macam senyawa kimia yang berasal dari asap kayu kedalam daging ikan, disertai dengan setengah pengeringan dan biasanya didahului dengan proses penggaraman. Pengolahan pengasapan dapat membuat ikan menjadi awet dan memungkinkan untuk didistribusikan dari pusat produksi ke pusat konsumen.

Salah satu jenis ikan yang dijadikan produk olahan tradisional yang terkenal di masyarakat Gorontalo yaitu ikan Julung-julung (Hemirhamphus sp.), yang dikenal oleh masyarakat dengan nama ikan roa atau sagela. Ikan sagela asap ini umumnya diolah kembali menjadi berbagai varian olahan seperti sambal sagela, bubur sagela, nasi goreng sagela, dan abon sagela. Varian olahan ikan sagela asap yang paling populer di masyarakat Gorontalo adalah sambal sagela yang memiliki keistimewaan citarasa yang khas yaitu sensasi perpaduan rasa ikan laut yang sudah diasapkan dengan rasa pedas yang menjadi ciri khas masyarakat "Celebes". Selain karakteristiknya yang enak dan gurih, produk ini juga merupakan ciri khas Provinsi Gorontalo di sektor perikanan.

Daerah penghasil ikan sagela asap di Provinsi Gorontalo adalah Desa Pasalae, Desa Bangga dan Desa Pentadu Barat. Harga ikan Sagela Asap yang berasal dari ketiga Desa ini bervariasi antara Rp 17.000,-/jepit - Rp 25.000,/jepit. Ikan sagela asap asal provinsi Gorontalo tidak hanya di pasarkan di dalam daerah sendiri tetapi sudah dipasarkan keluar daerah khususnya Manado. Hal ini dikarenakan tingginya permintaan akan ikan sagela asap di dalam daerah dan luar daerah Gorontalo.

Berdasarkan penjelasan di atas, beberapa pertanyaan dan permasalahan yang perlu diketahui jawabannya adalah sebagai berikut: (1) bagaimana sistem pemasaran ikan sagela asap mulai dari tangan produsen sampai ketangan konsumen, (2) bagaimana tingkat efisiensi pemasaran ikan sagela asap yang yang berasal dari Provinsi Gorontalo

Penelitian ini bertujuan untuk mengetahui proses pergerakan ikan sagela asap dari tangan produsen sampai ketangan konsumen yang ada di Provinsi Gorontalo, mengetahui besarnya margin pemasaran bagi tiap-tiap lembaga pemasar dan mengetahui tingkat efisiensi pemasaran ikan sagela asap yang berasal dari provinsi Gorontalo.

Berdasarkan alasan-alasan tersebut dianggap penting untuk melakukan penelitian mengenai Rantai Pasar Ikan Sagela Asap Asal Provinsi Gorontalo.

\section{METODE PENELITIAN}

\subsection{Lokasi dan Waktu Penelitian}

Penelitian dilaksanakan di Propinsi Gorontalo pada bulan Mei-Agustus 2018. Lokasi penelitian ditentukan secara purposive di daerah penghasil ikan sagela asap di Kabupaten Gorontalo Utara (Desa Pasalae), dan Kabupaten Boalemo (Desa Bangga dan Pentadu Barat). 


\subsection{Jenis dan Sumber Data}

Sumber data dalam penelitian ini berasal dari data primer dan data sekunder. Data primer dikumpulkan melalui penelitian lapangan dengan menggunakan metode pengumpulan data yang menggunakan beberapa teknik sekaligus seperti wawancara dengan menggunakan kuesioner, dokumentasi dan observasi. Wawancara dengan menggunakan kuesioner dilakukan terhadap responden produsen pedagang perantara ikan sagela asap. Jenis data yang dikumpulkan meliputi data jumlah produksi, harga jual, harga beli produk, biaya pemasaran dan tempat pemasaran produk. Sedangkan data sekunder diperoleh dari Dinas perindustrian Provinsi Gorontalo, Dinas Kelautan dan Perikanan Propinsi Gorontalo, Kantor Desa dan lembaga lain yang terkait dengan penelitian ini, baik berupa pustaka, hasil penelitian maupun laporan.

\section{Metode pengumpulan data}

Penentuan responden ditentukan secara Cluster Sampling (pengelompokan berdasarkan karakteristik responden: penghasil dan pedagang ;perantara). Responden dalam penelitian ini adalah produsen sagela sebanyak 8 orang, pedagang besar/pengumpul sebanyak 5 orang, supplier 1 orang dan 4 orang pedagang pengecer yang diambil secara sampling jenuh atau sensus.

Menurut Arikunto (2000) bahwa jika subyek penelitian kurang dari 100, lebih baik diambil semua sehingga penelitiannya merupakan penelitian populasi. Selanjutnya jika jumlah subyeknya besar, dapat diambil antara 5\%,10\%, 15\%, $20 \%$, dan $25 \%$ atau lebih, tergantung pada: (1) Kemampuan peneliti dilihat dari waktu, tenaga dan dana. (2) Sempit luasnya wilayah pengamatan dari subyek, Karena hal ini menyangkut banyak tidaknya data. (3) Besar kecilnya resiko yang ditanggung oleh peneliti. Untuk penelitian yang resikonya besar, tentu saja jika sampel besar hasilnya akan baik.

\section{1. $\quad$ Metode Analisis Data}

Model analisis yang digunakan adalah sebagai berikut:

\subsubsection{Analisis Deskriptif}

Analisis Deskriptif digunakan untuk menganalisis saluran pemasaran ikan sagela asap yang ada di Provinsi Gorontalo

\subsubsection{Analisis Marjin dan Keuntungan Pemasaran}

Formulasi Marjin pemasaran dan Keuntungan pemasaran yang digunakan berpedoman pada Hanafiah dan Saefuddin (1986):

$$
\begin{array}{cl}
\mathrm{Mp}= & \mathrm{Hp}-\mathrm{Hb} \\
\text { dimana : } & \\
\mathrm{Mp} & =\text { Marjin Pemasaran } \\
\mathrm{Hp} & =\text { Harga Penjualan } \\
\mathrm{Hb} & =\text { Harga Pembelian }
\end{array}
$$

Formulasi Keuntungan lembaga pemasaran yang digunakan adalah:

$$
\pi=\mathrm{M}-\mathrm{Bp}
$$




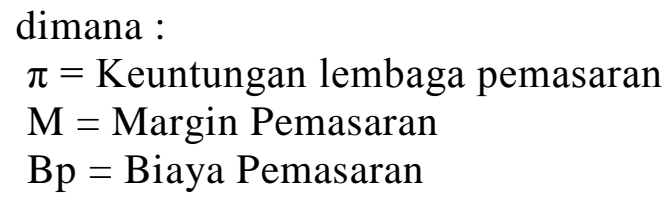

\subsubsection{Analisis Efisiensi Pemasaran}

Untuk mengetahui efisiensi pemasaran masing-masing saluran digunakan formula yaitu (Hanafiah dan Saefuddin, 1986):

$$
\mathrm{Ep}=\frac{B p}{N p} \times 100 \%
$$

$$
\begin{array}{ll}
\operatorname{dimana}: & \\
\mathrm{Ep} & =\text { Efisiensi Pemasaran } \\
\mathrm{Bp} & =\text { Biaya Pemasaran } \\
\mathrm{Np} & =\text { Nilai Produksi yang dipasarkan } \\
\mathrm{Ket} & : \text { yang dianggap paling efisien adalah yang menghasilkan nilai } \\
& \quad \text { terkecil. }
\end{array}
$$

\section{HASIL DAN PEMBAHASAN}

\subsection{Gambaran umum usaha pengasapan ikan Sagela di Provinsi}

\section{Gorontalo}

Di Provinsi Gorontalo terdapat beberapa daerah penghasil ikan sagela asap yaitu (1) Desa Pasalae, Kecamatan Gentuma Raya, Kabupaten Gorontalo Utara; (2) Desa Bangga, Kecamatan Paguyaman Pantai, Kabupaten Boalemo dan; (3) Desa Pentadu Barat, Kecamatan Tilamuta, Kabupaten Boalemo. Secara umum ikan sagela di Provinsi Gorontalo di produksi dalam skala kecil dan masih tergolong industri rumahan dengan peralatan tradisional. Musim penangkapan ikan julung-julung berlangsung antara bulan Maret-September sehingga usaha pengasapan ikan julung-julung asap (sagela) masih terkendala dengan ketersediaan bahan baku. Usaha pengasapan ini umumnya hanya berlangsung pada saat musim penangkapan ikan julung-julung dan terhenti jika musim penangkapan berakhir. Proses produksi ikan sagela terdiri atas: (1) proses penerimaan bahan baku; (2) proses penjepitan dan pengikatan. Ikan yang siap untuk diasapi dikemas dalam satu jepit yang terdiri dari 20 ekor ikan dengan masing-masing berat ikan mencapai 50 gr/ekor sehingga berat basah ikan yang akan diasapi dalam setiap jepit adalah $1 \mathrm{Kg}$; (3) proses pengasapan; (4) proses pengepakan. Pengepakan yang dilakukan untuk produk ikan julung-julung asap untuk pemasaran dibuat dalam bentuk ikat. Satu ikat atau pak produk ikan julungjulung matang berjumlah 10 jepit, dengan setiap jepit terdapat 20 ekor ikan julung-julung asap matang, sehingga total dalam satu ikat atau pak yaitu 200 ekor. Produksi ikan sagela asap sangat disukai oleh masyarakat Gorontalo karena cita rasanya enak dan gurih. Ikan sagela asap ini biasa dibeli oleh masyarakat gorontalo untuk dijadikan berbagai varian olahan diantaranya: sambal sagela, bubur sagela, nasi goreng sagela dan abon sagela. 
Di Desa pasalae terdapat 4 (empat) UKM yang melakukan kegiatan pengasapan ikan julung-julung (sagela). Kebutuhan bahan baku untuk setiap pengolah rata-rata $200-300 \mathrm{~kg}$ per satu kali produksi untuk semua pengolah dengan kapasitas produksi yaitu 300 Jepit ikan sagela per hari. 1 Jepit ikan sagela berisi 20 ekor ikan sagela asap. Harga ikan sagela ini cukup terjangkau yakni untuk harga eceran Rp. 20.000 per Jepit sedangkan untuk harga partai Rp. 17000Rp18.000 per Jepit.

Penghasil ikan asap di Desa Pentadu Barat ada 2 (dua) yaitu satu usaha rumah tangga dengan kapasitas produksi perbulan adalah pada musim puncak sekitar 2000 Jepit perbulannya sedangkan pada musim biasa hanya mampu berproduksi sekitar 1000 Jepit perbulannya dan satu lagi UKM dengan kapasitas produksi $300 \mathrm{Jepit} / \mathrm{hari}$.

Di Desa Bangga Terdapat 2 (dua) pengasap ikan julung-julung (sagela) dengan kebutuhan bahan-baku perhari sebanyak 100-250 ekor. Hasil produksi ikan sagela perharinya sekitar 10 dan 25 Jepit untuk masing-masing pengasap. Pemasaran hasil produksi ikan sagela asap di Desa Bangga adalah dijual langsung kepada pedagang besar yang ada di kota Gorontalo dengan harga jual antara Rp 22.000- Rp 23.000,- per jepitnya.

\subsection{Rantai pasar ikan sagela asap yang berasal dari Provinsi Gorontalo}

Lembaga tata niaga adalah orang yang terlibat dalam penyaluran barang dari produsen sampai ke konsumen akhir. Lembaga tata niaga yang terlibat dalam penyaluran hasil perikanan umumnya sedikit dan distribusinya pendek mengingat produk perikanan yang sifatnya perisahable dan mudah busuk. Hasil penelitian Luhur dan Yusuf, (2017) menunjukkan bahwa pemasaran ikan cakalang di Ambon memiliki saluran distribusi yang pendek dengan tiga saluran distribusi yaitu: (1) dari nelayan ke pedagang pengumpul ke pedagang pengecer; (2) dari nelayan ke pedagang pengumpul kemudian ke pengolah ikan asar; (3) dari nelayan ke UPI/cold storage. Bentuk saluran distribusi Ikan sagela asap yang diproduksi di Provinsi Gorontalo juga melalui rantai tata niaga yang sederhana, yaitu lembaga yang terlibat tidak terlalu banyak. Berikut adalah saluran tata niaga ikan sagela asap yang ada di Provinsi Gorontalo:

\subsubsection{Saluran tata niaga ikan sagela asap asal Desa Pasalae}

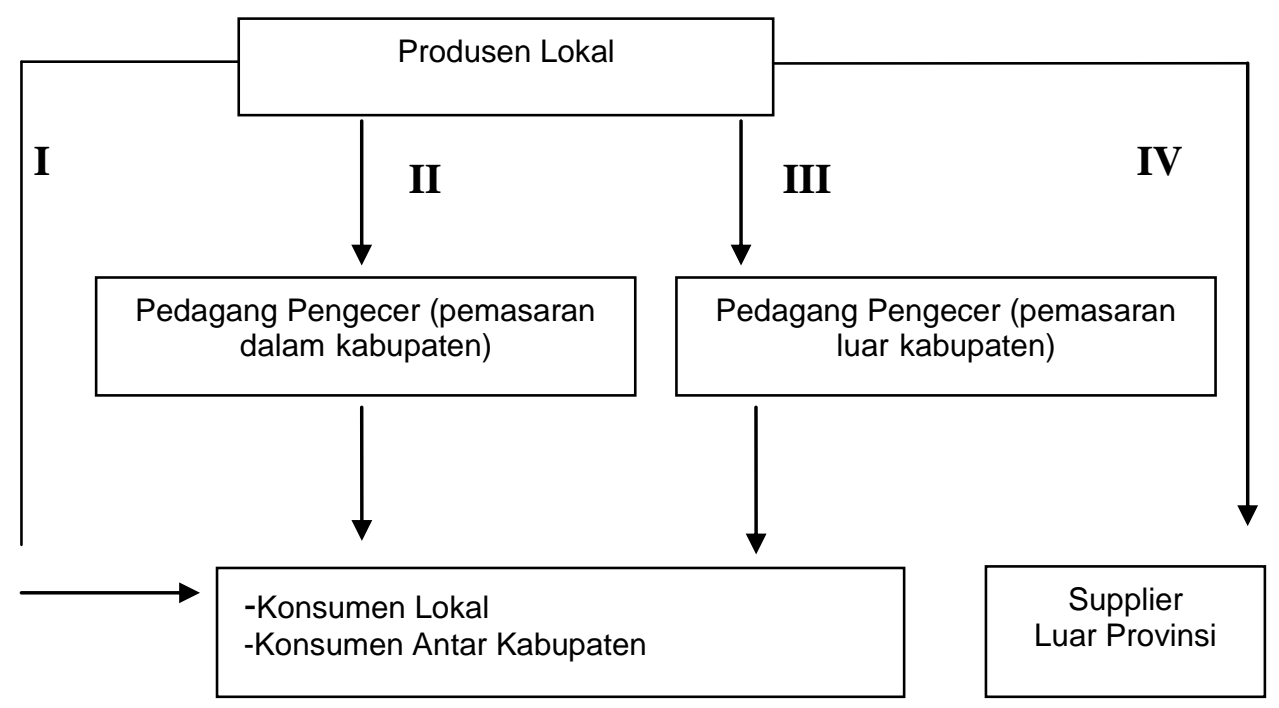


Gambar 1. Rantai pemasaran ikan sagela asap dari Desa Pasalae.

Rantai pemasaran ikan sagela asap dari Desa Pasalae ada 4 (empat) saluran yaitu: (1) dari produsen ke konsumen; (2) dari produsen ke pedagang pengecer (pemasaran dalam Kabupaten) kemudian ke konsumen lokal; (3) dari produsen ke pedagang pengecer (pemasaran luar Kabupaten) kemudian ke konsumen antar Kabupaten; (4) dari produsen ke supplier luar provinsi. Harga jual di tingkat produsen adalah Rp 17.000-Rp 18.000,-/jepit, dan harga jual di pedagang pengecer adalah Rp 20.000,-/jepit. Analisis biaya, marjin, keuntungan dan efisiensi pemasaran ikan sagela asap asal Desa Pasalae

Biaya pemasaran merupakan biaya-biaya yang dikeluarkan dalam proses pergerakan barang dari tangan produsen sampai ketangan konsumen akhir. Biayabiaya tersebut mempengaruhi besarnya perbedaan antara harga yang diterima oleh produsen dengan harga yang dibayarkan oleh konsumen. Tabel berikut merupakan gambaran besarnya biaya-biaya yang dikeluarkan dalam proses pergerakan ikan sagela asap dari produsen ke konsumen akhir.

Tabel 1. Biaya pemasaran ikan sagela asap asal Desa Pasalae.

\begin{tabular}{llr}
\hline \multirow{2}{*}{ Lembaga Pemasaran } & Uraian Biaya & \multicolumn{1}{c}{$\begin{array}{c}\text { Biaya } \\
\text { (Rp/Jepit) }\end{array}$} \\
\hline & Biaya bahan baku & 10000 \\
& Biaya tenaga kerja & 1750 \\
Pengasap/Produsen & Biaya bahan bakar + penjepit & 1450 \\
& B. peralatan & 700 \\
& B. transportasi & 1500 \\
\cline { 2 - 3 } & Total biaya & $\mathbf{1 5 4 0 0}$ \\
\hline Pedagang Pengecer (Pemasaran & Biaya transportasi & 200 \\
\cline { 2 - 3 } dalam Kab) & Total biaya & $\mathbf{2 0 0}$ \\
\hline Pedagang Pengecer (pemasaran & Biaya transportasi & 400 \\
\cline { 2 - 3 } Luar Kab) & Total biaya & $\mathbf{4 0 0}$ \\
\hline Supplier Luar Propinsi & Biaya transportasi & 150 \\
& Tenaga kerja & 2000 \\
\cline { 2 - 3 } & & $\mathbf{2 1 5 0}$ \\
\hline
\end{tabular}

Sumber Data : Data primer yang telah diolah, 2018.

Dari data diatas terlihat bahwa biaya yang dikeluarkan oleh pengasap/produsen ikan sagela terdiri atas biaya bahan baku, biaya tenaga kerja, biaya bahan bakar + penjepit, biaya peralatan dan biaya transportasi pengangkutan bahan baku dengan total biaya sebesar Rp 15.400,-/Jepit. Biaya pemasaran yang dikeluarkan oleh pedagang pengecer apabila memasarkan dalam kabupaten adalah biaya transportasi sebesar Rp 200,-/Jepit, biaya pemasaran yang dikeluarkan oleh pedagang pengecer apabila memasarkan di luar Kabupaten adalah biaya transportasi sebesar Rp 400/Jepit, biaya pemasaran yang dikeluarkan oleh supplier luar propinsi adalah biaya transportasi dan biaya tenaga kerja sebesar Rp 2.150,- /Jepit. 
Sementara itu margin pemasaran adalah selisih antara harga penjualan dengan harga pembelian. Perbedaan harga disebabkan adanya biaya dan keuntungan yang diharapkan. Sedangkan keuntungan pemasaran merupakan selisih harga yang dibayarkan konsumen dengan harga yang diterima oleh produsen setelah dikurangi dengan biaya pemasaran. Keuntungan dari suatu lembaga pemasaran tidak terlepas dari biaya pemasaran, dimana biaya pemasaran yang dikeluarkan adalah biaya pergerakan ikan sagela asap dari pengasap sampai ketangan konsumen akhir. Besarnya marjin dan keuntungan pemasaran oleh tiap lembaga pemasar ikan sagela asap dari Desa Pasalae, Kabupaten Gorontalo Utara dapat dilihat pada Tabel 2.

Tabel 2. Analisis Marjin dan Keuntungan Pemasaran Ikan Sagela Asap Asal Desa Pasalae

\begin{tabular}{|c|c|c|c|c|c|c|}
\hline \multirow{2}{*}{$\begin{array}{c}\text { Saluran } \\
\text { Pemasar } \\
\text { an }\end{array}$} & \multirow{2}{*}{$\begin{array}{l}\text { Lembaga } \\
\text { pemasaran }\end{array}$} & \multicolumn{2}{|c|}{$\begin{array}{c}\text { Harga Ikan Sagela } \\
\text { Asap }\end{array}$} & \multirow{2}{*}{$\begin{array}{c}\text { Marjin } \\
\text { Pemasar } \\
\text { an } \\
\text { (Rp/Jepi } \\
\text { t) }\end{array}$} & \multirow{2}{*}{$\begin{array}{c}\text { Biaya } \\
\text { Pemasar } \\
\text { an } \\
\text { (Rp/Jepi } \\
\text { t) }\end{array}$} & \multirow{2}{*}{$\begin{array}{c}\text { Keuntung } \\
\text { an } \\
\text { Pemasara } \\
\mathrm{n} \\
\text { (Rp/Jepit) }\end{array}$} \\
\hline & & $\begin{array}{l}\mathrm{Hb} \\
\text { (Rp/Jep } \\
\text { it) }\end{array}$ & $\begin{array}{l}\text { HP } \\
\text { (Rp/Jep } \\
\text { it) }\end{array}$ & & & \\
\hline \multirow{5}{*}{1} & Produsen & - & 18000 & - & 15400 & 2600 \\
\hline & Pedagang & & & & & \\
\hline & Pengecer & & & & & \\
\hline & $\begin{array}{l}\text { (PemasaranDa } \\
\text { lam Kab) }\end{array}$ & 18000 & 20000 & 2000 & 200 & 1800 \\
\hline & Saluran 1 & & & 2000 & 15600 & 4400 \\
\hline \multirow{6}{*}{ II } & Produsen & - & 18000 & - & 15400 & 2600 \\
\hline & Pedagang & & & & & \\
\hline & Pengecer & & & & & \\
\hline & (Pemasaran & & & & & \\
\hline & Luar Kab) & 18000 & 22000 & 4000 & 400 & 3600 \\
\hline & Saluran II & & & 4000 & 15800 & 6200 \\
\hline \multirow{2}{*}{ III } & Produsen & - & 18000 & - & 15400 & 2600 \\
\hline & Saluran III & & & - & 15400 & 2600 \\
\hline \multirow{4}{*}{ IV } & Produsen & - & 17000 & - & 15400 & 1600 \\
\hline & Supplier Luar & & & & & \\
\hline & Propinsi & 17000 & 25000 & 8000 & 2150 & 5850 \\
\hline & Saluran IV & & & 8000 & 17550 & 7450 \\
\hline
\end{tabular}

Sumber Data : Data primer yang telah diolah, 2018.

Dari data diatas terlihat bahwa pada saluran 1 total margin pemasaran adalah Rp 2.000,- biaya pemasaran sebesar Rp 15.600,-dan total keuntungan pemasaran pada saluran 1 sebesar Rp 4.400,-, pada saluran II total margin sebesar Rp 4.000,-total biaya pemasaran sebesar Rp 15.800,- dan total keuntungan pemasaran adalah sebesar Rp 6.200,- pada saluran III tidak ada margin pemasaran karena pemasaran dilakukan langsung dari produsen ke konsumen,total biaya pemasaran sebesar Rp 15.400,- dan total keuntungan pemasaran sebesar Rp 2.600,- sedangkan pada saluran IV total margin pemasaran sebesar Rp 
8.000,- total biaya pemasaran sebesar Rp 17.550 ,- dan total keuntungan lembaga pemasaran sebesar Rp 7.450,-.

Dari semua lembaga pemasaran yang terlibat dalam pergerakan ikan sagela asap yang berasal dari Desa Pasalae, yang memiliki jumlah pembelian dan keuntungan terbesar adalah Supplier luar propinsi dengan nilai keuntungan pemasaran sebesar $\mathrm{Rp}$ 5.850,-/Jepit. Besarnya keuntungan yang diperoleh lembaga pemasaran berkaitan dengan jumlah biaya yang dikeluarkan. Semakin besar biaya yang dikeluarkan semakin besar pula perolehan keuntungan yang diharapkan, begitu juga sebaliknya. Jadi suatu kewajaran yang ada bila keuntungan yang besar dimiliki oleh lembaga pemasaran yang juga berani menanggung kerugian yang relatif besar (Pusat Studi Terumbu Karang Unhas, 2002)

Semua kegiatan pemasaran menghendaki adanya sesuatu yang disebut efisiensi, yaitu pengorbanan serendah mungkin sehingga mencapai tingkat kepuasan yang diinginkan. Efisiensi yang dimaksud disini adalah efisiensi pemasaran ikan sagela asap yang berasal dari Desa Pasalae, Kabupaten Gorontalo Utara. Berdasarkan hasil penelitian maka besarnya efisiensi pemasaran pada setiap lembaga pemasaran dapat dilihat pada Tabel 3.

Tabel 3. Analisis Efisiensi Pemasaran Tiap Lembaga Pemasaran Ikan Sagela Asap Asal Desa Pasalae.

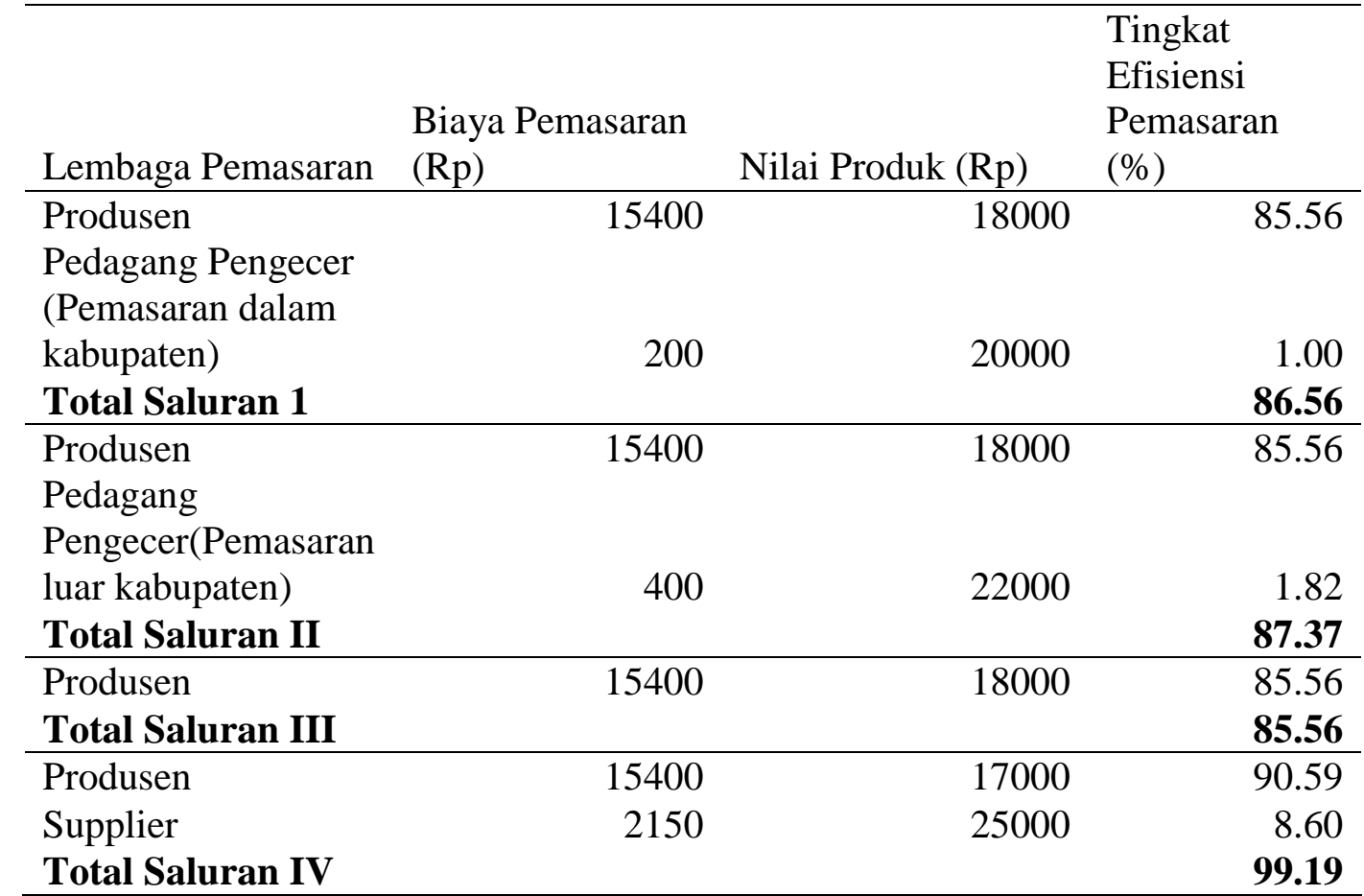

Sumber Data : Data primer yang telah diolah, 2018.

Dari data diatas dapat terlihat bahwa saluran pemasaran ikan sagela asap asal Desa Pasalae pada saluran 1 (dari produsen ke pedagang pengecer dalam kabupaten kemudian ke konsumen akhir) adalah sebesar $86,56 \%$, pada saluran II (dari produsen ke pedagang pengecer luar kabupaten kemudian ke konsumen akhir) adalah sebesar 87,37\%, pada saluran III (dari produsen ke konsumen akhir) sebesar 85,56\%, pada saluran IV ( dari produsen ke supplier luar propinsi 
kemudian ke konsumen) sebesar 99,19\%. Dari ke -4 (empat) saluran pemasaran ikan sagela asap asal Desa Pasalae yang paling efisien adalah saluran III (dari produsen ke konsumen) dengan nilai $\mathrm{Ep}=85.56 \%$. Hal ini berdasarkan kriteria (Hanafiah dan Saefuddin, 1986) yang menyatakan bahwa saluran pemasaran yang dianggap paling efisien adalah yang menghasilkan nilai terkecil. Sedangkan lembaga pemasaran yang paling efisien untuk pemsaran ikan sagela asap asal Desa Pasalae adalah pedagang pengecer (pemasaran di dalam kabupaten) dengan nilai efisiensi pemasaran yang paling kecil yaitu $1 \%$. Efisiennya lembaga pemasaran pedagang pengecer (pemasaran didalam kabupaten) ini disebabkan oleh rendahnya biaya pemasaran yang dikeluarkan oleh pedagang pengecer dibanding dengan lembaga pemasaran yang lain.

\subsubsection{Saluran tata niaga ikan sagela asap dari Desa Bangga}

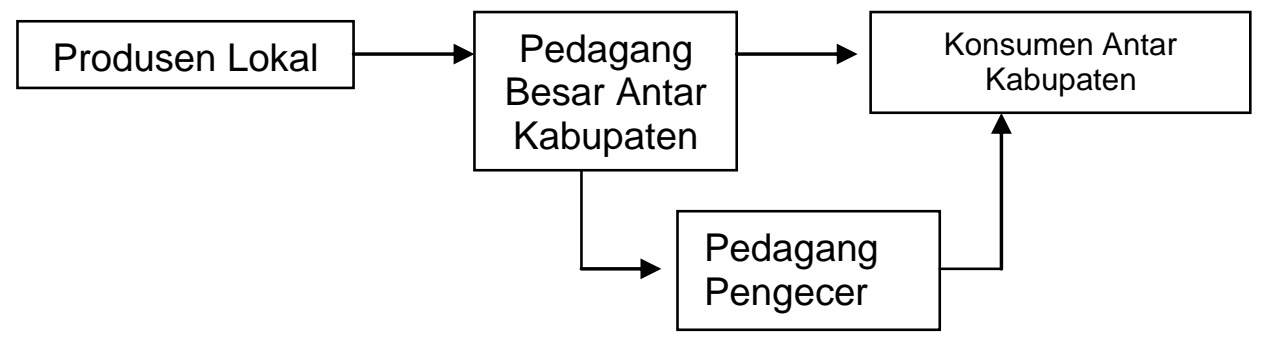

Gambar 2. Rantai pemasaran ikan sagela asap dari Desa Bangga

Rantai pemasaran ikan sagela asap dari Desa Bangga ada 2 (dua) saluran yaitu: (1) dari produsen ke pedagang besar antar kabupaten kemudian ke konsumen; (2) dari produsen ke pedagang besar antar kabupaten kemudian pedagang besar menjual ke pedagang pengecer dan pedagang pengecer mendistribusikan ke konsumen. Harga jual di tingkat produsen adalah Rp 22.000/jepit, harga jual di pedagang besar Rp 23.000,-/jepit dan harga jual di pedagang pengecer adalah Rp 25.000,-/jepit.

Tabel 4. Biaya Pemasaran Ikan sagela Asap Asal Desa Bangga

Lembaga Pemasaran $\quad$ Uraian Biaya $\quad$ Biaya (Rp/Jepit)

\begin{tabular}{llr}
\hline & Biaya bahan baku & 15000 \\
& Biaya Tenaga Kerja & 1750 \\
Pengasap/Produsen & Biaya Bahan Bakar + & \\
& Penjepit & 1450 \\
& B.Peralatan & 700 \\
& B. Transportasi & 1500 \\
& Total Biaya & $\mathbf{2 0 4 0 0}$ \\
\hline Pedagang Pengecer & Biaya Transportasi & 200 \\
\cline { 2 - 3 } & Total Biaya & $\mathbf{2 0 0}$ \\
\hline Pedagang Besar & Biaya Transportasi & 250 \\
& Biaya Penyimpanan & 1000 \\
& Total Biaya & $\mathbf{1 2 5 0}$ \\
\hline
\end{tabular}


Sumber Data : Data primer yang telah diolah, 2018.

Dari data diatas terlihat bahwa biaya yang dikeluarkan oleh pengasap/produsen ikan sagela terdiri atas biaya bahan baku, biaya tenaga kerja, biaya bahan bakar + penjepit, biaya peralatan dan biaya transportasi pengangkutan bahan baku dengan total biaya sebesar Rp 20.400,-/Jepit. Biaya pemasaran yang dikeluarkan oleh pedagang pengecer adalah biaya transportasi sebesar Rp 200,/Jepit, biaya pemasaran yang dikeluarkan oleh pedagang besar adalah biaya transportasi dan biaya penyimpanan sebesar Rp 1.250,- /Jepit.

Tabel 5. Analisis Marjin dan Keuntungan Pemasaran Ikan Sagela Asap Asal Desa Bangga

\begin{tabular}{|c|c|c|c|c|c|c|}
\hline \multirow{2}{*}{$\begin{array}{c}\text { Saluran } \\
\text { Pemasara } \\
\text { n }\end{array}$} & \multirow[b]{2}{*}{$\begin{array}{l}\text { Lembaga } \\
\text { pemasaran }\end{array}$} & \multicolumn{2}{|c|}{$\begin{array}{c}\text { Harga Ikan Sagela } \\
\text { Asap }\end{array}$} & \multirow{2}{*}{$\begin{array}{c}\text { Marjin } \\
\text { Pemasara } \\
n \\
\text { (Rp/Jepit } \\
\text { ) }\end{array}$} & \multirow{2}{*}{$\begin{array}{c}\text { Biaya } \\
\text { Pemasara } \\
n \\
\text { (Rp/Jepit } \\
\text { ) }\end{array}$} & \multirow{2}{*}{$\begin{array}{c}\text { Keuntung } \\
\text { an } \\
\text { Pemasaran } \\
\text { (Rp/Jepit) }\end{array}$} \\
\hline & & $\begin{array}{l}\mathrm{Hb} \\
\text { (Rp/Jepi } \\
\mathrm{t})\end{array}$ & $\begin{array}{l}\text { HP } \\
\text { (Rp/Jepi } \\
\text { t) }\end{array}$ & & & \\
\hline \multirow{4}{*}{1} & Produsen & - & 22000 & - & 20400 & 1600 \\
\hline & Pedagang & & & & & \\
\hline & Besar & 22000 & 25000 & 3000 & 1250 & 1750 \\
\hline & Saluran 1 & & & 3000 & 21650 & 3350 \\
\hline \multirow{6}{*}{ II } & Produsen & - & 22000 & - & 20400 & 1600 \\
\hline & Pedagang & & & & & \\
\hline & Besar & 22000 & 23000 & 1000 & 250 & 750 \\
\hline & Pedagang & & & & & \\
\hline & Pengecer & 23000 & 25000 & 2000 & 200 & 1800 \\
\hline & $\begin{array}{l}\text { Saluran } \\
\text { II }\end{array}$ & & & 3000 & 20850 & 4150 \\
\hline
\end{tabular}

Sumber Data : Data primer yang telah diolah, 2018.

Dari data diatas terlihat bahwa pada saluran 1 total margin pemasaran adalah Rp 3.000,- biaya pemasaran sebesar Rp 21.650,-dan total keuntungan pemasaran pada saluran 1 sebesar Rp 3.350,-, pada saluran II total margin sebesar Rp 3.000,-total biaya pemasaran sebesar Rp 20.850,- dan total keuntungan pemasaran adalah sebesar Rp 4.150,- . Dari semua lembaga pemasaran yang terlibat dalam pergerakan ikan asap dari produsen ke konsumen yang memiliki keuntungan pemasaran tertinggi adalah pedagang pengecer. Tingginya keuntungan pemasaran yang di peroleh pedagang pengecer pada saluran II karena pada saluran II antara pedagang besar dan pedagang pengecer berbagi biaya pemasaran sehingga semakin rendah biaya pemasaran yang dikeluarkan oleh pedagang pengecer.

Tabel 6. Analisis Efisiensi Pemasaran Tiap Lembaga Pemasaran Ikan Sagela Asap Asal Desa Bangga.

\begin{tabular}{lrrr}
\hline Lembaga Pemasaran & Biaya Pemasaran & Nilai Produk & \multicolumn{1}{c}{$\begin{array}{l}\text { Efisiensi } \\
\text { Pemasaran }\end{array}$} \\
\hline Produsen & 20400 & 22000 & 92.73
\end{tabular}


Pedagang Besar

1250

25000

Saluran 1

Produsen

20400

22000

92.73

Pedagang Besar

250

23000

1.09

Pedagang Pengecer

200

25000

0.80

Saluran II

93.82

Sumber Data : Data primer yang telah diolah, 2018

Dari data diatas dapat terlihat bahwa saluran pemasaran ikan sagela asap asal Desa Pasalae pada saluran 1 (dari produsen ke pedagang besar kemudian ke konsumen akhir) adalah sebesar $98.16 \%$, pada saluran II (dari produsen ke pedagang besar kemudian pedagang pengecer selanjutnya ke konsumen akhir) adalah sebesar $93,82 \%$. Saluran pemasaran yang dianggap paling efisien adalah Saluran II dengan nilai Ep $=93,82 \%$ dengan nilai yang lebih kecil dari saluran I . Pada saluran II lebih efisien meskipun rantai pemasarannya lebih panjang daripada saluran I karena pada saluran II biaya yang dikeluarkan oleh pedagang besar dan pedagang pengecer lebih sedikit. Hal ini menyebabkan harga jual produk yang ditawarkan juga lebih rendah dibanding pada saluran I. pada saluran II antara pedagang besar dan pedagang pengecer berbagi biaya pemasaran sehingga bisa lebih efisien dibanding saluran I yang semua biaya pemasarannya di tanggung oleh pedagang besar. Hal ini sejalan dengan pendapat Mubyarto (1997) yang menyatakan bahwa sistem tata niaga dianggap efisien bila memenuhi 2 (dua) syarat yaitu: (1) mampu menyampaikan hasil-hasil dari produsen ke konsumen dengan biaya semurah-murahnya, (2) mampu mengadakan pembagian yang adil dari keseluruhan harga yang dibayar konsumen terakhir kepada semua pihak yang ikut serta dalam kegiatan produksi dan tata niaga barang tersebut.

\subsubsection{Saluran tata niaga ikan sagela asap dari Desa Pentadu Barat}

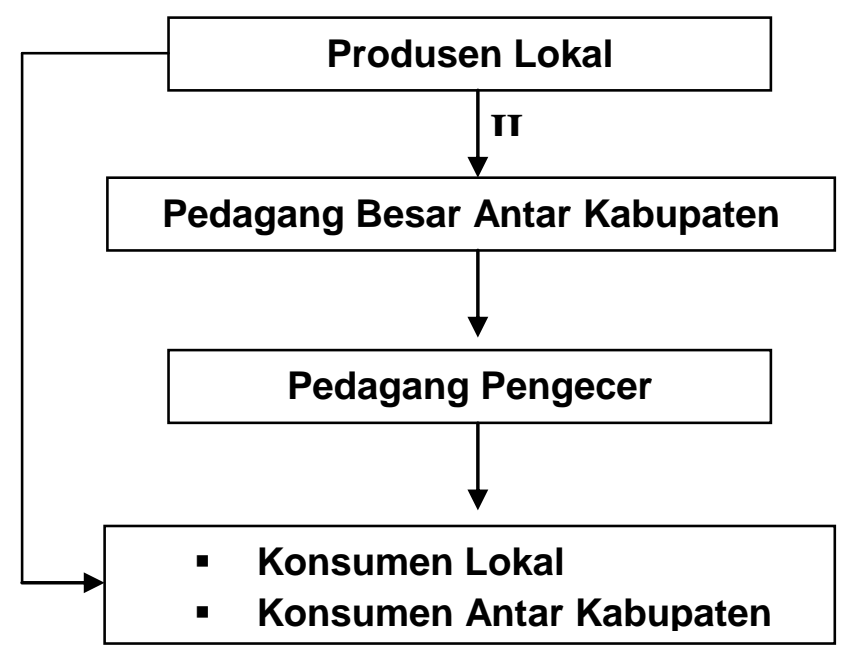

Gambar 3. Skema rantai pemasaran ikan sagela asap dari Desa Pentadu Barat 
Rantai pemasaran ikan sagela asap dari Desa Pentadu Barat ada 2 (dua) saluran yaitu: (1) dari produsen ke konsumen; (2) dari produsen ke pedagang besar antar kabupaten kemudian pedagang besar menjual ke pedagang pengecer dan pedagang pengecer mendistribusikan ke konsumen. Rantai pemasaran ikan sagela asap yang berasal dari Desa Pentadu Barat tergolong pendek hal ini sesuai dengan pendapat (Kotler, 2001) yang menyatakan bahwa usaha-usaha memperpendek mata rantai pemasaran/tataniaga adalah salah satu jalan membantu petani untuk meningkatkan pendapatannya. Umumnya saluran pemasaran yang terpendek memberikan penerimaan yang terbesar dan resiko pemasaran yang terkecil bagi produsen. Harga jual di tingkat produsen adalah Rp 22.000-/jepit, harga jual di pedagang besar Rp 23.000,-/jepit dan harga jual di pedagang pengecer adalah Rp 25.000,-/jepit. Analisis Biaya, Marjin, Keuntungan dan Efisiensi Pemasaran Ikan Sagela Asap Desa Pentadu Barat

Tabel 7. Biaya Pemasaran Ikan sagela Asap Asal Desa Pentadu Barat

\begin{tabular}{llr}
\hline \multirow{2}{*}{ Lembaga Pemasaran } & \multicolumn{1}{c}{ Uraian Biaya } & Biaya (Rp/Jepit) \\
& & \\
\hline & Biaya bahan baku & 15000 \\
& Biaya Tenaga Kerja & 1750 \\
Pengasap/Produsen & Biaya Bahan Bakar + & \\
& Penjepit & 1450 \\
& B.Peralatan & 700 \\
& B. Transportasi & 1500 \\
& Total Biaya & $\mathbf{2 0 4 0 0}$ \\
\hline Pedagang Pengecer & Biaya Transportasi & 200 \\
\cline { 2 - 3 } & Total Biaya & $\mathbf{2 0 0}$ \\
\hline Pedagang Besar & Biaya Transportasi & 250 \\
& & $\mathbf{2 5 0}$ \\
\hline
\end{tabular}

Sumber Data : Data primer yang telah diolah, 2018.

Dari data diatas terlihat bahwa biaya yang dikeluarkan oleh pengasap/produsen ikan sagela terdiri atas biaya bahan baku, biaya tenaga kerja, biaya bahan bakar + penjepit, biaya peralatan dan biaya transportasi pengangkutan bahan baku dengan total biaya sebesar Rp 20.400,-/Jepit. Biaya pemasaran yang dikeluarkan oleh pedagang pengecer adalah biaya transportasi sebesar Rp 200,/Jepit, biaya pemasaran yang dikeluarkan oleh pedagang besar adalah biaya transportasi sebesar Rp 250,- /Jepit.

Tabel 8. Analisis Marjin dan Keuntungan Pemasaran Ikan Sagela Asap Dari Kabupaten Boalemo.

\begin{tabular}{|c|c|c|c|c|c|c|}
\hline \multirow{2}{*}{$\begin{array}{c}\text { Saluran } \\
\text { Pemasaran }\end{array}$} & \multirow{2}{*}{$\begin{array}{c}\text { Lembaga } \\
\text { pemasaran }\end{array}$} & \multicolumn{2}{|c|}{$\begin{array}{c}\text { Harga Ikan Sagela } \\
\text { Asap }\end{array}$} & \multirow{2}{*}{$\begin{array}{c}\text { Marjin } \\
\text { Pemasaran } \\
\text { (Rp/Jepit) }\end{array}$} & \multirow{2}{*}{$\begin{array}{c}\text { Biaya } \\
\text { Pemasaran } \\
\text { (Rp/Jepit) }\end{array}$} & \multirow{2}{*}{$\begin{array}{c}\text { Keuntungan } \\
\text { Pemasaran } \\
\text { (Rp/Jepit) }\end{array}$} \\
\hline & & $\begin{array}{l}\mathrm{Hb} \\
\text { (Rp/Jepit) }\end{array}$ & $\begin{array}{l}\text { HP } \\
\text { (Rp/Jepit) }\end{array}$ & & & \\
\hline I & Produsen & - & 22000 & - & 20400 & 1600 \\
\hline
\end{tabular}


Pedagang

Besar

22000

23000

1000

250

750

Pedagang

Pengecer

23000

25000

2000

200

1800

Saluran

II

3000

20850

4150

Produsen

22000

20400

1600

II Saluran

III

20400

1600

Sumber Data : Data primer yang telah diolah, 2018.

Dari data diatas terlihat bahwa pada saluran I total margin sebesar Rp 3.000,-total biaya pemasaran sebesar Rp 20.850,- dan total keuntungan pemasaran adalah sebesar Rp 4.150,-. Pada saluran II total margin pemasaran tidak ada margin pemasaran karena distribusi ikan sagela asap langsung dari tangan produsen ke tangan konsumen. Biaya pemasaran yang dilakukan oleh produsen sebesar Rp 20.400,- dengan total keuntungan pemasaran sebesar Rp 1.600,- . dari semua lembaga pemasaran yang terlibat dalam pergerakan ikan asap dari produsen ke konsumen yang memiliki keuntungan pemasaran tertinggi adalah pedagang pengecer disebabkan oleh rendahnya biaya pemasaran yang harus dikeluarkan oleh pedagang pengecer.

Tabel 9. Analisis Efisiensi Pemasaran Tiap Lembaga Pemasaran Ikan Sagela Asap dari, Kabupaten Boalemo.

\begin{tabular}{|c|c|c|c|}
\hline Lembaga Pemasaran & $\begin{array}{l}\text { Biaya } \\
\text { Pemasaran }\end{array}$ & $\begin{array}{l}\text { Nilai } \\
\text { Produk }\end{array}$ & $\begin{array}{l}\text { Tingkat Efisiensi } \\
\text { Pemasaran }(\%)\end{array}$ \\
\hline Produsen & 20400 & 22000 & 92.73 \\
\hline Pedagang Besar & 250 & 23000 & 1.09 \\
\hline Pedagang Pengecer & 200 & 25000 & 0.80 \\
\hline Saluran I & & & 93.82 \\
\hline Produsen & 20400 & 22000 & 92.73 \\
\hline Saluran II & & & 92.73 \\
\hline
\end{tabular}

Sumber : Data primer yang telah diolah, 2018.

Dari data diatas dapat terlihat bahwa saluran pemasaran ikan sagela asap asal Desa Pentadu Barat pada saluran 1 (Dari produsen ke pedagang besar kemudian ke pedagang pengecer selanjutnya ke konsumen akhir) adalah sebesar 93.82\%, pada saluran II (dari produsen ke konsumen akhir) adalah sebesar $92.73 \%$, Dari ke 2 (dua) saluran pemasaran ikan sagela asap asal Desa Pentadu Barat yang paling efisien adalah saluran II (dari produsen ke konsumen) dengan nilai $\mathrm{Ep}=92,73 \%$. Lebih kecil dibanding nilai pada saluran $\mathrm{I}$.

\section{KESIMPULAN DAN SARAN}

\subsection{Kesimpulan}

Bentuk Saluran tata niaga ikan sagela asap asal Provinsi Gorontalo yaitu mulai dari produsen baik itu produsen kemudian menjualnya ke pedagang besar, supplier dan pedagang pengecer untuk seterusnya ke konsumen. Margin tertinggi 
ikan asap asal Desa Pasalae sebesar Rp 8.000,-, dan margin tertinggi ikan asap asal Desa Bangga dan Desa Pentadu Barat sebesar Rp 3.000,-. Lembaga pemasaran yang dianggap paling efisien adalah pedagang pengecer dengan nilai efisiensi pemasaran terendah dibanding semua lembaga pemasaran yang ada. Efisiennya lembaga pemasaran pedagang pengecer ini disebabkan oleh rendahnya biaya pemasaran yang dikeluarkan oleh pedagang pengecer dibanding dengan lembaga pemasaran yang lain. Sedangkan saluran pemasaran yang paling efisien untuk ikan sagela asap asal Desa Pasalae dan Pentadu Barat adalah saluran yang langsung dari produsen ke konsumen sedangkan di Desa Bangga saluran pemasaran yang efisien adalah saluran yang dari produsen ke pedagang besar kemudian ke pedagang pengecer selanjutnya ke konsumen

\subsection{Saran}

Perlu dilakukan efisiensi biaya bahan baku mengingat tingginya biaya produksi ikan sagela asap di tingkat produsen/pengasap. Untuk meminimalkan biaya bahan baku perlu upaya pembenahan dari hulu untuk menjamin ketersediaan bahan baku, pembenahan pelabuhan nelayan, peningkatan jumlah perahu nelayan lengkap dengan mesin dan jaring (alat tangkap). Perlu adanya peran pemerintah dalam mengintervensi harga faktor-faktor produksi agar tidak terlalu tinggi guna menumbuhkembangkan industri-industri skala kecil yang bergerak di bidang pengolahan ikan tradisional khususnya pengasapan ikan sagela. Saluran pemasaran ikan asap yang paling efisien adalah saluran yang dari produsen langsung ke konsumen sehingga disarankan bagi konsumen sebaiknya membeli langsung ke produsen agar harga pembelian tidak terlalu tinggi.

\section{DAFTAR PUSTAKA}

Arikunto, S. 2000. Prosedur Penelitian Suatu Pendekatan Praktek. Penerbit Rineka Cipta. Yogyakarta.

Hanafiah, A.M. dan Saefuddin. 1986. Tata Niaga Hasil Perikanan. Universitas Indonesia. Jakarta.

Mubyarto. 1997. Pengantar Teori Mikroekonomi. Edisi ke-2 . PT Raja Grafindo. Jakarta.

Luhur, E.S dan Yusuf, R. 2017. Analisis Rantai Nilai Ikan Cakalang di Kota Ambon, Maluku. Jurnal J. Sosek KP Vol 12 (1): 93-105

Kotler, Philip. 1997. Manajemen Pemasaran Analisis Perencanaan, Implementasi dan Pengendalian (terjemahan Jaka Wasana). Salemba Empat. Jakarta

Kotler, Philip. 2003. Manajemen dan Strategi Pemasaran. Erlangga . Jakarta.

Sulistijowati, R. S. Djunaedi, O.S. Nurhajati, J. Afrianto, E. Udin, Z. 2011. Mekanisme Pengasapan Ikan. UNPAD Press. Bandung.

Soekartawi. 1998. Pengantar Agroindustri. Raja Grafindo Persada. Jakarta.

Pusat Studi Terumbu Karang Unhas, 2002. Studi Jaringan Pemasaran Produk Perikanan Dari Taman Nasional Laut Takabonerate Kabupaten Selayar. Universitas Hasanuddin, Makassar. 